\title{
MATHEMATICAL MODELLING OF THERMAL AND FLOW PROCESSES IN VERTICAL GROUND HEAT EXCHANGERS
}

\author{
Sebastian Pater*, Włodzimierz Ciesielczyk \\ Cracow University of Technology, Department of Chemical and Process Engineering, Warszawska \\ 24, 31-155 Kraków, Poland
}

The main task of mathematical modelling of thermal and flow processes in vertical ground heat exchanger (BHE-Borehole Heat Exchanger) is to determine the unit of borehole depth heat flux obtainable or transferred during the operation of the installation. This assignment is indirectly associated with finding the circulating fluid temperature flowing out from the U-tube at a given inlet temperature of fluid in respect to other operational parameters of the installation.

The paper presents a model of thermal and flow processes in BHE consisting of two analytical models separately-handling processes occurring inside and outside of borehole. A quasi-threedimensional model formulated by Zeng was used for modelling processes taking place inside the borehole and allowing to determine the temperature of the fluid in the U-tube along the axis of BHE. For modelling processes occurring outside the borehole a model that uses the theory of linear heat source was selected. The coupling parameters for the models are the temperature of the sealing material on the outer wall of the borehole and the average heat flow rate in BHE. Experimental verification of the proposed model was shown in relation to BHE cooperating with a heat pump in real conditions.

Keywords: vertical ground heat exchanger, borehole, geothermal heat pumps, thermal and flow processes

\section{INTRODUCTION}

Under Polish conditions heating or cooling systems with so-called ground heat pumps often cooperate with a BHE (Wiśniewska and Forysiak, 2014). In vertical boreholes of depth from several tens to up to $200 \mathrm{~m}$ the single U-tube has been widely used. The empty space between the pipe and the wall of the borehole is filled with the sealing material. The heat transport medium flowing through the U-pipe extracts heat from the ground surrounding the borehole as well as from the groundwater (if present), and transports it to the refrigerant in an evaporator of the heat pump. If the heat pump works in cooling mode, the heat from the upper heat source is transmitted into the ground. Heat transport in BHE occurs by convection from the fluid to the wall of the U-tube and subsequently by sealing of the borehole to the ground mainly by conduction. In the areas of active groundwater exchange this process takes place also by convection.

The main task of mathematical modelling of thermal and flow processes in BHE is to determine the unit of borehole depth heat flux obtainable or transferred during the work of the installation (Koziol, 2012). The analytical models describing the processes occurring in BHE most commonly separately examine the phenomena arising inside and outside the borehole (Rees, 2016; Salimshirazi, 2012). 
The main area of modelling thermal and flow processes inside BHE is to determine the fluid temperature at the inlet and outlet of the U-tube, depending on temperature of the borehole wall and mass flow rate of a fluid, with the assumed physicochemical data of fluid, sealing material and U-tube pipe (Koohi-Fayegh and Rosen, 2014). For a rough computational analysis a simplified onedimensional model shown at work (Gu and O'Neal., 1998) can be used. This model omits the axial changes of borehole material, heat capacity and also thermal interaction between the circulating medium flowing in U-tube. Hellström (1991) developed an analytical solution of thermal resistance between the pipes in U-tube in the cross-section perpendicular to the axis of the borehole. On the basis of this model a quasi-three-dimensional model formulated by Zeng (Zeng et al., 2003) was created, which takes into account temperature changes of the fluid along the axis of the borehole with neglected axial heat conduction.

One of the first analytical models for a quantitative description of the thermal and flow processes outside BHE was a model using the theory of linear heat source (Kelvin's line source) presented in (Ingersoll and Plass, 1948). In this model, soil is treated as a medium with an initial uniform temperature in the entire volume and the borehole with the U-tube is assumed to be an infinite line source. In the cylindrical source model (Wołoszyn, 2014) the borehole is considered as an infinite cylinder surrounded by a homogeneous material with properties being constant over time. Eskilson (1987) presented a model that takes into account the axial changes of ground temperature with time and depth. The temperature distribution on the outer wall of the borehole BHE was determined as so-called $" g$ " function which represents a specific configuration of the boreholes (Rees, 2016). The finite line source model developed by Zeng's team (Zeng et al., 2002) uses the model proposed by Eskilson. The temperature distribution in the borehole can be obtained by solving analytical equations. Integration of these equations is faster than numerically solving this problem (Zeng et al., 2002).

In recent years, thanks to increased computing capacity, numerical models of thermal and flow processes in BHE are dynamically developing (Yang et al., 2010). These models offer the possibility to include, among others, heat flow inside and outside the borehole, the spatial changes of physicochemical properties of soil and sealing material of the borehole, interaction between the boreholes in BHE and also changes of boundary conditions in time and space (Wołoszyn, 2014). Due to the high slenderness ratio of BHE (small diameter compared to length) and a large number of elements in three-dimensional mesh calculations carried out in the simulation programs can be extremely time consuming. Publications by Śliwa et al. $(2005,2011,2012)$ should also be mentioned.

Performing computations using numerical models despite the fact that they may offer a high degree of flexibility and accuracy is not justified if there is no reliable information on the physicochemical properties of the soil surrounding the borehole (Koziol, 2012). Analytical models of thermal and flow processes in BHE are developed mainly for practical reasons, because they allow to perform calculations in a quick and relatively simple way in comparison to numerical models (Yang et al., 2010).

The paper presents a model of thermal and flow processes in BHE consisting of two analytical models separately handling processes occurring inside and outside of the borehole. For modelling processes taking place inside the borehole a quasi-three-dimensional model formulated by Zeng (Zeng et al., 2003) was used, which:

- allows determining the temperature of the fluid in the U-tube along the axis of BHE,

- takes into account the heat exchange between the pipes which are being arranged symmetrically in a borehole,

- assumes identical temperature on the external wall of borehole along its axis, which however can vary with time,

- assumes a homogeneous structure of the ground material and the sealing of the borehole, whose physicochemical properties are independent of temperature (Zeng et al., 2003). 
The model does not take into account heat conducted in axial direction, heat transferred by convection from the groundwater and the phase transition of the moisture in the borehole sealing.

For modelling processes occurring outside the borehole a model that uses the theory of linear heat source (Ingersoll, 1948) was selected. It assumes:

- initial uniform temperature of soil (so called undisturbed ground temperature) and constant thermo-physical parameters in the entire volume,

- one-dimensional heat conduction without heat conduction in the axial direction (also from the surface above and below of the borehole),

- heat exchange between the outer wall of borehole and the surrounding soil.

The coupling parameters for models are the temperature of the sealing material on the outer wall of the borehole and the average heat flow rate in BHE. The average heat flow rate at specified intervals remains constant, but may vary between these intervals.

\section{MODEL OF THERMAL AND FLOW PROCESSES IN BHE}

Energy balance equations for the fluid flowing up and down in the U-tube (Zeng et al., 2003) were formulated as (1) and (2):

$$
\begin{aligned}
& -\dot{m}_{s} c_{s} \frac{d T_{f 1}}{d z}=\frac{T_{f 1}-T_{b}}{R_{1}^{\Delta}}+\frac{T_{f 1}-T_{f 2}}{R_{12}^{\Delta}} \\
& \dot{m}_{s} c_{s} \frac{d T_{f 2}}{d z}=\frac{T_{f 2}-T_{b}}{R_{2}^{\Delta}}+\frac{T_{f 2}-T_{f 1}}{R_{12}^{\Delta}}
\end{aligned}
$$

Expressions $R_{1}^{\Delta}, R_{2}^{\Delta}$ and $R_{12}^{\Delta}$ are calculated from Eqs. $(3,4,5)$ :

$$
\begin{aligned}
& R_{1}^{\Delta}=\frac{R_{11} R_{22}-R_{12}^{2}}{R_{22}-R_{12}} \\
& R_{2}^{\Delta}=\frac{R_{11} R_{22}-R_{12}^{2}}{R_{11}-R_{12}} \\
& R_{12}^{\Delta}=\frac{R_{11} R_{22}-R_{12}^{2}}{R_{12}}
\end{aligned}
$$

$R_{11}$ and $R_{22}$ represent a thermal resistance between the wall of the borehole and the fluid. $R_{12}$ is the thermal resistance between the flowing fluids in the pipes (Fig. 1). Because the pipes in the borehole are located symmetrically it is assumed that $R_{11}=R_{22}$.

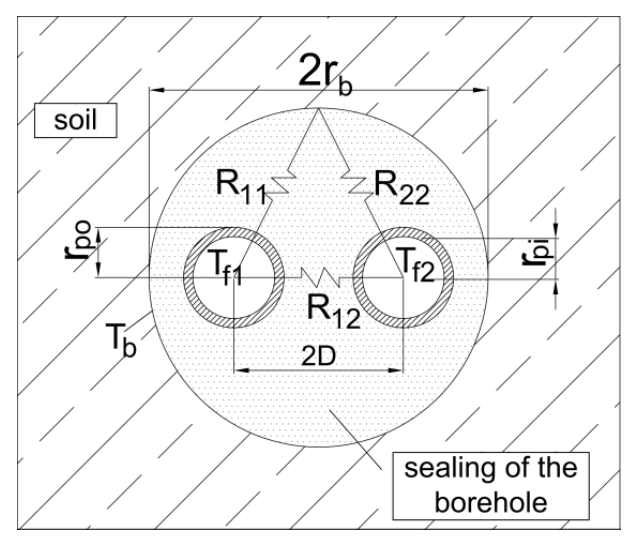

Fig. 1. The cross-section of borehole with U-tube 
Hellstrom (1991) specified Eqs. (6) and (7) describing the thermal resistances $R_{11}$ and $R_{12}$ as follows:

$$
\begin{gathered}
R_{11}=\frac{1}{2 \pi k_{b}}\left[\ln \left(\frac{r_{b}}{r_{p o}}\right)+\frac{k_{b}-k_{g}}{k_{b}+k_{g}} \cdot \ln \left(\frac{r_{b}^{2}}{r_{b}^{2}-D^{2}}\right)\right]+R_{p} \\
R_{12}=\frac{1}{2 \pi k_{b}}\left[\ln \left(\frac{r_{b}}{2 D}\right)+\frac{k_{b}-k_{g}}{k_{b}+k_{g}} \cdot \ln \left(\frac{r_{b}^{2}}{r_{b}^{2}+D^{2}}\right)\right]
\end{gathered}
$$

The value of the thermal resistance $R_{p}$ from fluid to the outer pipe surface is determined (Zhang et al., 2015) from Eq. (8) as:

$$
R_{p}=\frac{1}{2 r_{p i} \pi h}+\frac{\ln \left(r_{p o} / r_{p i}\right)}{2 \pi k_{p}}
$$

The coefficient $h_{f}$ was estimated from Dittus-Boelter correlation (9):

$$
h=0.0115 \operatorname{Re}^{0.8} \operatorname{Pr}^{n} \frac{k_{f}}{r_{p i}}
$$

Depending on the operating mode of the heat pump factor $n$ takes a value 0.40 for heating and 0.33 for cooling mode. To solve the energy balance Eqs. (1) and (2), the following boundary conditions were assumed (10):

$$
\left.\begin{array}{cc}
z=0, & T_{f 1}=T_{f}^{\prime} \\
z=H, & T_{f 1}=T_{f 2}
\end{array}\right\}
$$

Using the Laplace transform (Zeng et al., 2003) the solutions of Eqs. (1) and (2) are given by Eqs. (11) and (12):

$$
\begin{aligned}
& \Theta_{1}(Z)= \cosh (\beta Z)-\frac{1}{\sqrt{1-P^{2}}}\left[1-P \frac{\cosh (\beta)-\sqrt{\frac{1-P}{1+P}} \sinh (\beta Z)}{\cosh (\beta)+\sqrt{\frac{1-P}{1+P}} \sinh (\beta)}\right] \sinh (\beta Z) \\
& \Theta_{2}(Z)= \frac{\cosh (\beta)-\sqrt{\frac{1-P}{1+P}} \sinh (\beta)}{\cosh (\beta)+\sqrt{\frac{1-P}{1+P}} \sinh (\beta)} \cosh (\beta Z)+ \\
&+\frac{1}{\sqrt{1-P^{2}}}\left[1-P \frac{\cosh (\beta)-\sqrt{\frac{1-P}{1+P}} \sinh (\beta)}{\cosh (\beta)+\sqrt{\frac{1-P}{1+P}} \sinh (\beta)}-P\right] \sinh (\beta Z)
\end{aligned}
$$

Dimensionless coefficients used in Eqs. (11) and (12) are defined by:

$$
\begin{gathered}
\Theta=\frac{T_{f}(z)-T_{b}}{T_{f}^{\prime}-T_{b}} \\
\beta=\frac{H}{\dot{m} c_{s} \sqrt{\left(R_{11}+R_{12}\right)\left(R_{11}-R_{12}\right)}} \\
Z=\frac{z}{H}
\end{gathered}
$$




$$
P=\frac{R_{12}}{R_{11}}
$$

The ground temperature depending on the distance from the linear heat source and time, for the average heat flux (Fang et al., 2002) is calculated from Eq. (17):

$$
T_{g}(r, t)=T_{\infty}+\frac{\bar{q}}{4 \pi H k_{g}} \operatorname{Ei}\left(\frac{r^{2}}{4 t \alpha}\right)
$$

The exponential integral in Eq. (17) can be approximated (Fang et al., 2002) by Eq. (18):

$$
\mathrm{Ei}\left(\frac{r^{2}}{4 t \alpha}\right)=\ln \left(\frac{4 t \alpha}{r^{2}}\right)-\gamma
$$

Under real conditions a value of the heat exchanged in BHE varies with time due to e.g. different demand for heating or cooling for industrial process or in the building construction. In order to apply the model under considerations to predict the operating parameters of BHE under varying conditions it must be assumed that at certain intervals the heat flux remains constant, while between these intervals, this heat flux may change. Using the technique of superposition (Fang et al., 2002) increase or decrease of the soil temperature can be determined from Equation (19):

$$
T_{g}(r, t)=T_{\infty}+\sum_{i=1}^{n} \frac{\left(\bar{q}_{i}-\bar{q}_{i-1}\right)}{4 \pi H k_{g}}\left[\ln \left(\frac{4 \alpha\left(t_{n}-t_{i-1}\right)}{r^{2}}\right)-\gamma\right]
$$

Precision of calculations based on Eq. (19) is dependent on the length of assumed intervals. If the value $5 r_{b}^{2} / \alpha$ is smaller than the length of the time interval, the error of estimation of the soil temperature with respect to the accurate model (e.g. numerical model) and a model of a linear heat source is less than $10 \%$ (Salimshirazi, 2012). Increasing the time interval to a value greater than $20 r_{b}^{2} / \alpha$, reduces the error to about 3\% (Salimshirazi, 2012).

The coupling parameters for the models are the temperature of the sealing material on the outer wall of the borehole and the average heat flow rate in the BHE in a specified time interval. The calculation algorithm proposed in (Koohi-Fayegh and Rosen, 2014) is based on determining the soil temperature $T_{g}$ from the linear source model for a given heat flux $\bar{q}$ in the time interval and distance from the source equal to $r_{b}$. Knowing the temperature $T_{b}$ it is possible to determine $T_{f 2}$ using Eq. (20):

$$
T_{f 2}(0)=T_{b}+\left(T_{f}^{\prime}-T_{b}\right) \Theta_{2}(0)
$$

Equation (12) simplifies to the form (21):

$$
\Theta_{2}(0)=\frac{\cosh (\beta)-\sqrt{\frac{1-P}{1+P}} \sinh (\beta)}{\cosh (\beta)+\sqrt{\frac{1-P}{1+P}} \sinh (\beta)}
$$

In Eq. (20) the temperature $T_{f}^{\prime}$ can be determined from Eq. (22):

$$
T_{f}^{\prime}=T_{f 2}(0)-\frac{\bar{q}}{\dot{m}_{s} c_{s}}
$$

By combining Eqs. (20) and (22), Eqs. (23) and (24) were obtained enabling to calculate $T_{f}^{\prime}$ and $T_{f 2}(0)$ in a given time step: 


$$
\begin{gathered}
T_{f}^{\prime}=T_{b}-\frac{\bar{q}}{\dot{m}_{s} c_{s}\left[1-\Theta_{2}(0)\right]} \\
T_{f 2}(0)=T_{b}-\frac{\bar{q} \Theta_{2}(0)}{\dot{m}_{s} c_{s}\left[1-\Theta_{2}(0)\right]}
\end{gathered}
$$

Because the proposed model is intended for an analysis including a variable heating and cooling load of a building or installation within a year, as well as varying degrees of this load coverage by a heat pump, the value of the average heat flux at a given time interval for a different operating mode of the heat pump is determined from Eqs. (25) and (26):

$$
\begin{gathered}
\bar{q}=\frac{\left(Q_{k}-\frac{Q_{k}}{\mathrm{SPF}}\right) \phi}{t_{k}} \\
\bar{q}=-\frac{Q_{k, C} \phi}{t_{k}}
\end{gathered}
$$

\section{EXPERIMENTAL VERIFICATION OF MODEL}

Experimental verification of the proposed model was shown in relation to BHE cooperating in real conditions with a compressor brine-water heat pump. The heat pump heating output was approx. $10 \mathrm{~kW}$ and the cooling output approx. $3 \mathrm{~kW}$ (in passive cooling mode). In the BHE three boreholes, each of which had a depth of 70 meters, were installed. The boreholes were made in one line, with seven meter intervals and six meters away from the northern wall of the building. In each borehole, a single polyethylene U-tube was mounted. The intermediate fluid which transmitted energy from the ground to the evaporator was aqueous propylene glycol solution.

Below $4 \mathrm{~m}$ in depth the soil surrounding the boreholes in the BHE was made of clays with low water permeability. In addition, by maintaining an appropriate distance between the boreholes limiting their thermal interaction, in the further part of the article heat-flow processes were considered for only one single borehole in BHE.

Table 1 presents the physicochemical properties of materials used in BHE and other data. Table 2 shows calculated values of the necessary parameters for the model verification. The value of $T_{\infty}$ was

\begin{tabular}{|c|c|c|c|c|c|}
\hline Parameter & Value & Parameter & Value & Parameter & Value \\
\hline$H[\mathrm{~m}]$ & 70 & $r_{b}[\mathrm{~m}]$ & 0.0675 & $\delta_{s}\left[\mathrm{~kg} / \mathrm{m}^{3}\right]$ & 1045 \\
\hline$D[\mathrm{~m}]$ & 0.0338 & $r_{p i}[\mathrm{~m}]$ & 0.0163 & $c_{g}[\mathrm{~J} /(\mathrm{kg} \cdot \mathrm{K})]$ & 800 \\
\hline$k_{b}[\mathrm{~W} /(\mathrm{m} \cdot \mathrm{K})]$ & 1.000 & $r_{p o}[\mathrm{~m}]$ & 0.0200 & $c_{s}[\mathrm{~J} /(\mathrm{kg} \cdot \mathrm{K})]$ & 3636 \\
\hline$k_{f}[\mathrm{~W} /(\mathrm{m} \cdot \mathrm{K})]$ & 0.385 & $T_{\infty}[\mathrm{K}]$ & 285.15 & $\mu_{s}[\mathrm{~kg} /(\mathrm{m} \cdot \mathrm{s})]$ & 0.00935 \\
\hline$k_{g}[\mathrm{~W} /(\mathrm{m} \cdot \mathrm{K})]$ & 2.200 & $\delta_{g}\left[\mathrm{~kg} / \mathrm{m}^{3}\right]$ & 1800 & $\dot{m}_{s}[\mathrm{~kg} / \mathrm{s}]$ & 0.198 \\
\hline$k_{p}[\mathrm{~W} /(\mathrm{m} \cdot \mathrm{K})]$ & 0.400 & & & & \\
\hline
\end{tabular}
determined based on the paper by Fidorów and Szulgowska-Zgrzywa (2015) in which the real temperature values of the soil surrounding BHE in the Polish climate were presented.

Table 1. The physicochemical properties of the materials used in single borehole and other data 
Table 2. The calculated values of the necessary parameters for model verification

\begin{tabular}{|c|c|c|c|}
\hline Parameter & Value & Parameter & Value \\
\hline$h\left[\mathrm{~W} /\left(\mathrm{m}^{2} \cdot \mathrm{K}\right)\right]$ & $\begin{array}{l}351.9 \text { (for heating) } \\
257.2 \text { (for cooling) }\end{array}$ & $R_{p}[\mathrm{~m} \cdot \mathrm{K} / \mathrm{W}]$ & $\begin{array}{l}0.109 \text { (for heating) } \\
0.119 \text { (for cooling) }\end{array}$ \\
\hline$\alpha\left[\mathrm{m}^{2} / \mathrm{s}\right]$ & $1.53 \times 10^{-6}$ & $P[-]$ & $\begin{array}{l}0.0406 \text { (for heating) } \\
0.0406 \text { (for cooling) }\end{array}$ \\
\hline$R_{11}[\mathrm{~m} \cdot \mathrm{K} / \mathrm{W}]$ & $\begin{array}{l}0.318 \text { (for heating) } \\
0.328 \text { (for cooling) }\end{array}$ & $\beta[-]$ & $\begin{array}{l}0.306 \text { (for heating) } \\
0.296 \text { (for cooling) }\end{array}$ \\
\hline$R_{12}[\mathrm{~m} \cdot \mathrm{K} / \mathrm{W}]$ & $1.33 \times 10^{-2}$ & $\Theta_{2}(0)[-]$ & $\begin{array}{l}0.557 \text { (for heating) } \\
0.567 \text { (for cooling) }\end{array}$ \\
\hline
\end{tabular}

Verification of the proposed model was conducted by determining the temperature of the brine flowing out from the U-tube at a given temperature of the fluid flowing into the U-tube for the time interval equal to $6 \mathrm{~h}$. Due to the fact that in the considered installation the time of continuous operation of the heat pump usually does not exceed a few hours, only for over a dozen days in several years of heat pump operation data were available and used for further calculations.

Figure 1 shows measured changes of fluid temperature at the inlet and the outlet of U-tube on 16 February 2012 during the operation of the heat pump in heating mode. Figure 3 presents theoretical changes of fluid temperature at the inlet and the outlet of U-tube on 16 February 2012. The theoretical change of fluid temperature in U-tube was determined from 6.00 to 12.00 and was equal to $3.39{ }^{\circ} \mathrm{C}$. The average experimental temperature difference of fluid at the inlet and the outlet of BHE (dotted rectangle in Fig. 2) was $3.48{ }^{\circ} \mathrm{C}$. The absolute value of the relative error of the determination of the fluid temperature difference was $2.6 \%$.
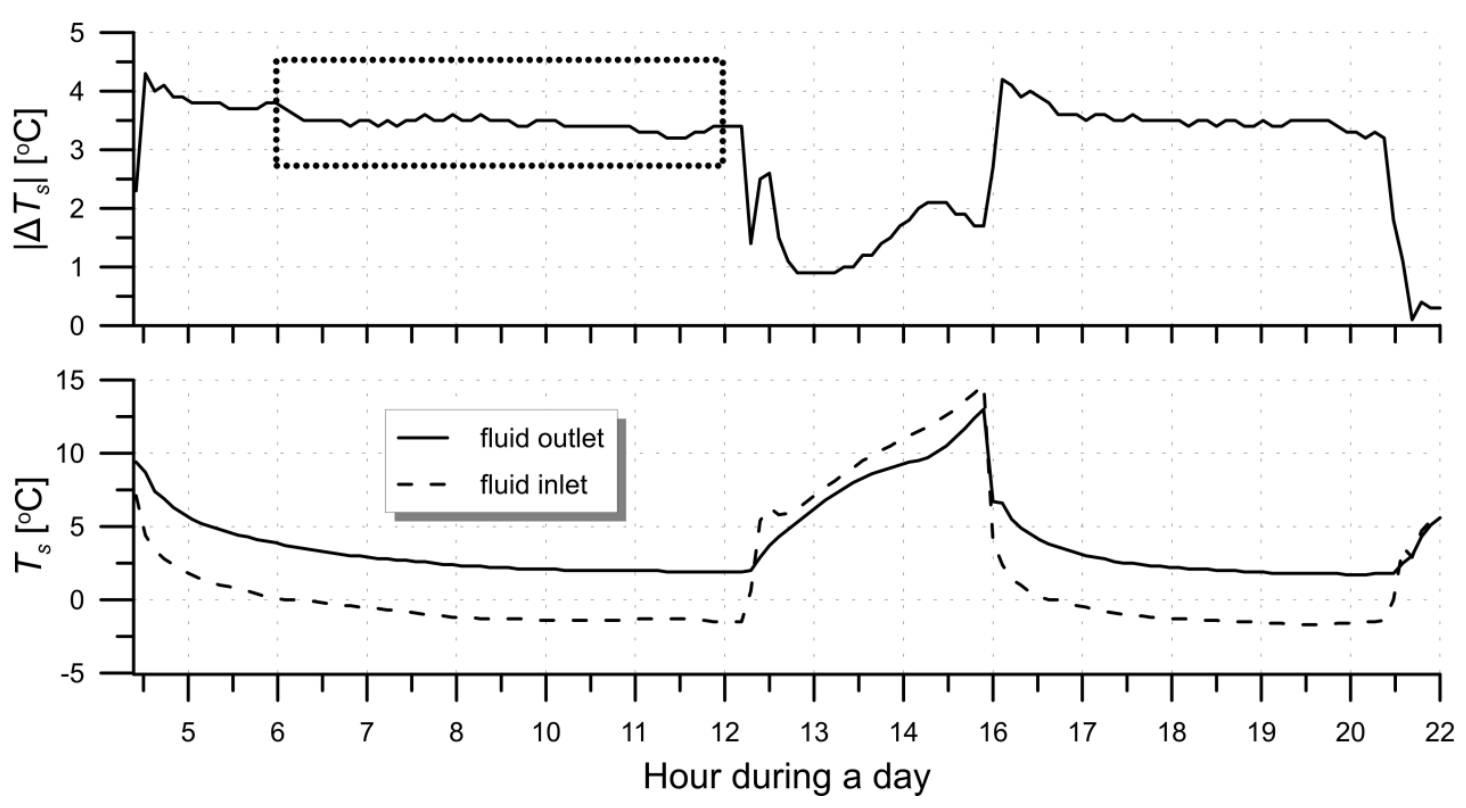

Fig. 2. Experimental changes of fluid temperature in inlet and outlet of U-tube on 16 February 2012 


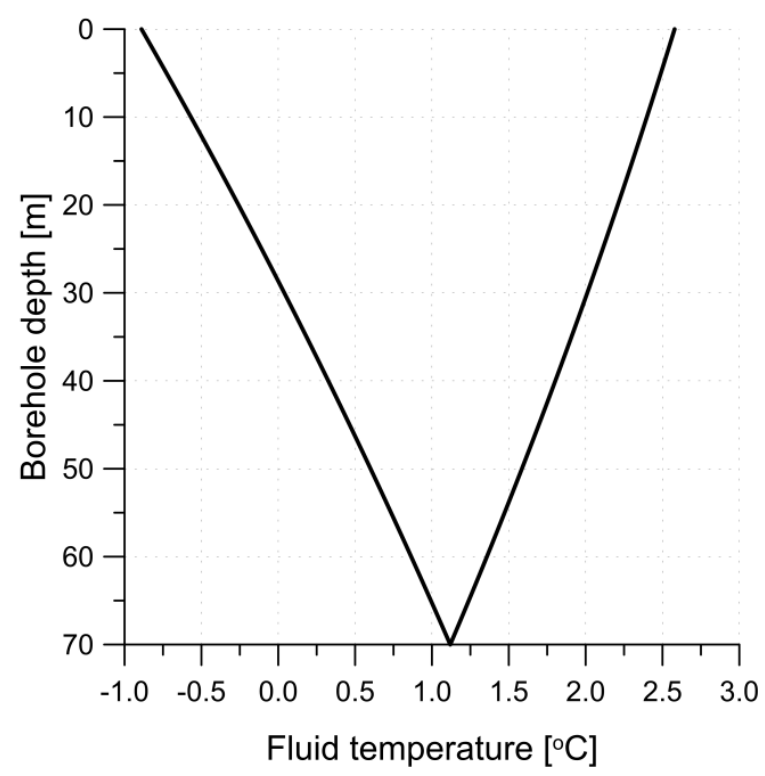

Fig. 3. Theoretical changes of fluid temperature in U-tube on 16 February 2012

The described procedure was carried out for several time periods in different years of BHE operation. For given time intervals the real average temperature difference of the fluid at the inlet and the outlet of the U-tube in BHE (Fig. 4) was determined. Then, using the developed mathematical model the temperature of soil on the inner surface of borehole and the fluid temperature at the outlet of U-tube was calculated. The absolute value of the relative error calculated theoretically does not exceed $16 \%$ of the measured value.

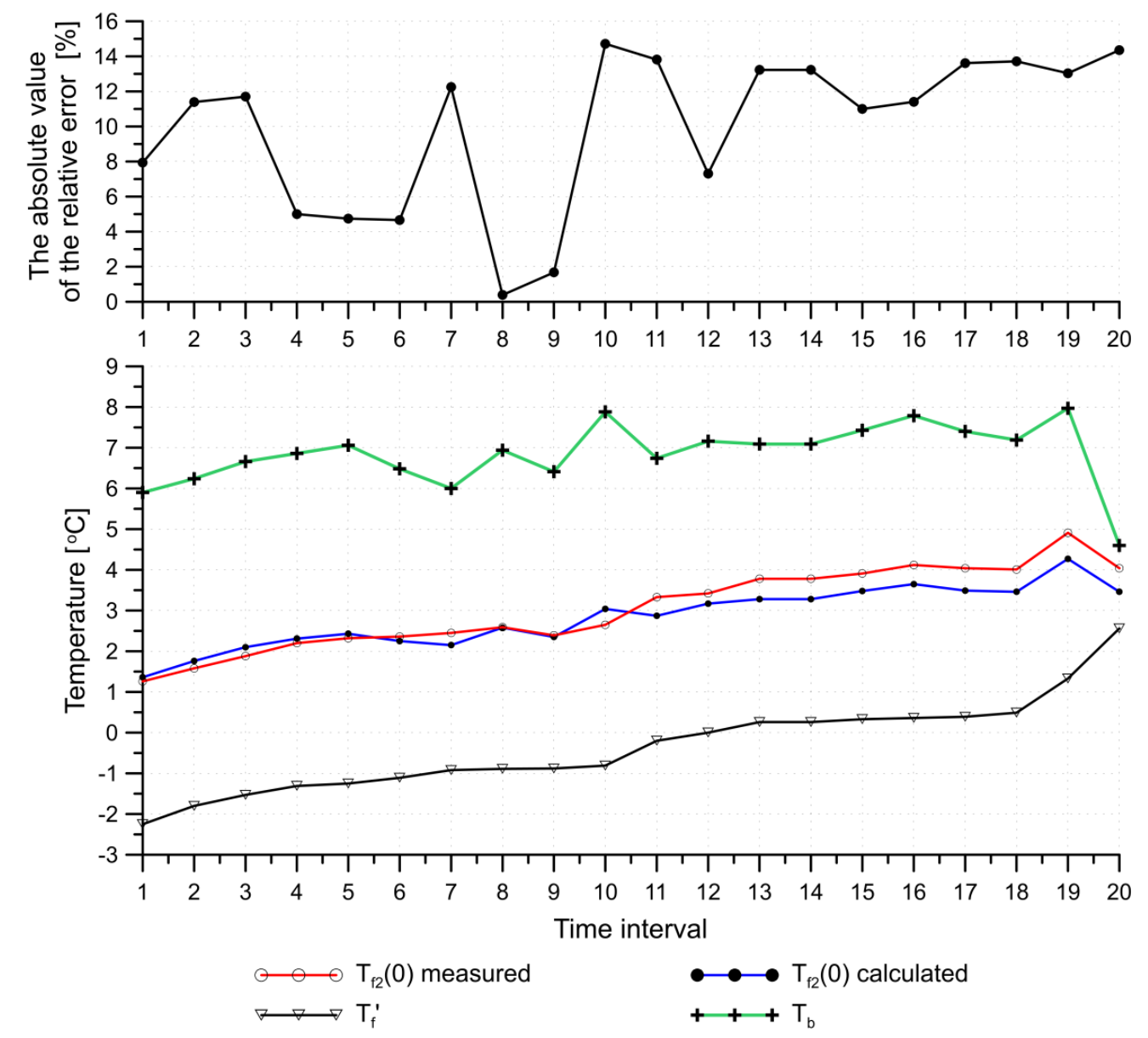

Fig. 4. Comparison of theoretical calculations with measurement data 


\section{CONCLUSIONS}

The proposed model of the thermal and flow processes in BHE allows to perform analyses involving long-term cooperation of the heat pump with BHE during heating seasons, the natural thermal regeneration of soil, regeneration of soil by accumulating the heat from the cooling process, as well as supplied from e.g. solar collectors, variable heating and cooling load of a building over the years and different degree of coverage of the heat demand for the building by the heat pump. The model allows to perform calculations related to the BHE in a relatively simple and quick way compared with numerical models. By using equations possible to be analytically solved obtaining the results of multivariate simulations of the operating conditions does not take much time.

Since the model does not take into account the thermal interaction between multiple boreholes which are in close proximity, its use is limited to a single borehole BHE. This model can be used for analysis of BHE with more boreholes if:

- in BHE the minimum distances between the boreholes which limit their thermal interaction are maintained,

- they are of equal depth,

- the ground surrounding the boreholes is additionally characterised by low permeability.

Experimental verification of the model proved that it is quantitatively in good agreement with experiments. Calculations were performed on a computer with an AMD Turion X2 Ultra clocked at $2.20 \mathrm{GHz}, 3 \mathrm{~GB}$ of RAM and a graphics card Radeon HD 3450. Calculation of the soil temperature at a distance $r=r_{b}$ for 1216 time intervals lasting $24 \mathrm{~h}$ has been done in Microsoft Excel in a few seconds.

\section{SYMBOLS}

$c \quad$ specific heat of the fluid, $\mathrm{J} /(\mathrm{kg} \cdot \mathrm{K})$

$D \quad$ distance between the pipes in a borehole, $\mathrm{m}$

Ei exponential integral

$h \quad$ coefficient of heat transfer from the brine to the surface of the pipe, $\mathrm{W} /\left(\mathrm{m}^{2} \cdot \mathrm{K}\right)$

$H \quad$ depth of the borehole, $\mathrm{m}$

$k \quad$ thermal conductivity, $\mathrm{W} /(\mathrm{m} \cdot \mathrm{K})$

$\dot{m} \quad$ mass flow rate, $\mathrm{kg} / \mathrm{s}$

$n \quad$ coefficient depending on the operating mode of the heat pump

$P \quad$ dimensionless coefficient

$\operatorname{Pr} \quad$ Prandtl number

$\bar{q} \quad$ average heat flux, $\mathrm{W}$

$Q \quad$ amount of heat exchanged, J

$r \quad$ radius, $\mathrm{m}$

Re Reynolds number

$t \quad$ time, $\mathrm{s}$

$T \quad$ temperature, $\mathrm{K}$

$z \quad$ coordinate axis, $\mathrm{m}$

$Z \quad$ dimensionless coefficient

A constant

Greek symbols

$\alpha \quad$ soil thermal diffusivity, $\mathrm{m}^{2} / \mathrm{s}$

$\beta \quad$ dimensionless coefficient 
$\gamma \quad$ Euler-Mascheroni constant

$\Delta T \quad$ temperature difference, $\mathrm{K}$

$\Theta \quad$ dimensionless temperature of the fluid

$\phi \quad$ coverage of demand for heating or cooling by heat pump in the time interval

\section{Superscripts \\ inlet}

\section{Subscripts}

1 fluid flowing down in U-tube

2 fluid flowing up in U-tube

$b \quad$ outer wall of borehole

c cool

$g \quad$ soil surrounding the borehole

$f \quad$ fluid

$k \quad$ time interval

$m \quad$ material filling the borehole

$p \quad$ pipe wall

$p i \quad$ inner wall of the pipe in a borehole

po outer wall of the pipe in a borehole

$s \quad$ fluid in U-tube

$\infty \quad$ undisturbed ground

\section{Abbreviations}

SPF Seasonal Performance Factor of Heat Pump

BHE Borehole Heat Exchanger

\section{REFERENCES}

Eskilson P., 1987. Thermal analysis of heat extraction boreholes. PhD thesis, University of Lund, Sweden.

Fang Z., Diao N., Cui P., 2002. Discontinuous operation of geothermal heat exchangers. Tsinghua Sci. Technol., 7, 194-201.

Fidorów N., Szulgowska-Zgrzywa M., 2015. The influence of the ground coupled heat pump's labor on the ground temperature in the boreholes - Study based on experimental data. Appl. Therm. Eng., 82, 237-245. DOI: 10.1016/j.applthermaleng.2015.02.035.

Gu Y., O'Neal D. L., 1998. Development of an equivalent diameter expression for vertical U-Tubes used in ground-coupled heat pumps. ASHRAE Trans., 104, 347-55.

Hellstrom G., 1991. Ground heat storage: Thermal analyses of duct storage systems. PhD thesis, University of Lund, Sweden.

Ingersoll L.H., Plass H.J., 1948. Theory of the ground pipe heat source for the heat pump. ASHVE Trans., 47, 339-348.

Koohi-Fayegh S., Rosen M., 2014. An analytical approach to evaluating the effect of thermal interaction of geothermal heat exchangers on ground heat pump efficiency. Energ. Convers. Manage., 78, 184-192. DOI: 10.1016/j.enconman.2013.09.064.

Kozioł J., 2012. Przeglad uwarunkowań i metod oceny efektywności wykorzystania odnawialnych źródet energii $w$ budownictwie. Wydawnictwo Politechniki Śląskiej, Gliwice.

Rees S., 2016. Advances in ground-source heat pump systems. Woodhead Publishing, Duxford.

Salimshirazi A., 2012. Transient heat transfer in vertical ground heat exchanger. PhD thesis, Polytechnique Montreal, Canada.

Śliwa T., Gonet A., 2005. Theoretical model of borehole heat exchanger. J. Energy Resour. Technol., 127, 142148. DOI:10.1115/1.1877515. 
Śliwa T., Gonet A., 2011. Analiza efektywności wymiany ciepła w wymiennikach otworowych o różnej konstrukcji. Wiertnictwo Nafta Gaz, 28, 555-570.

Śliwa T., Gołaś A., Wołoszyn J., Gonet A. (2012). Numerical model of borehole heat exchanger in ANSYS CFX software. Arch. Min. Sci., 57, 375-390. DOI 10.2478/v10267-012-0024-3.

Wołoszyn J., 2014. Badania wpływu rozmieszczenia wymienników na efektywność podziemnych magazynów energii. PhD thesis, AGH University of Science and Technology, Poland.

Wiśniewska M., Forysiak J., 2014. Źródła ciepła niskotemperaturowego dostępnego dla gruntowych pionowych wymienników ciepła. Uwarunkowania środowiskowe i techniczne. Acta Universitatis Lodziensis, Folia Geographica Physica, 13, 65-77.

Yang H., Cui P., Fang Z., 2010. Vertical-borehole ground-coupled heat pumps: A review of models and systems. Appl. Energy, 87, 16-27. DOI: 10.1016/j.apenergy.2009.04.038.

Zeng H., Diao N., Fang Z., 2002. A finite line-source model for boreholes in geothermal heat exchangers. Heat Tran. Asian. Res., 31, 558-567. DOI: 10.1002/htj.10057.

Zeng H., Diao N., Fang Z., 2003. Efficiency of vertical geothermal heat exchangers in the ground source heat pump system. J. Thermal Sci.. 12, 77-81. DOI: 10.1007/s11630-003-0012-1.

Zhang C., Chen P., Liu Y., Sun S., Peng D., 2015. An improved evaluation method for thermal performance of borehole heat exchanger. Renew. Energy, 77, 142-151. DOI: 10.1016/j.renene.2014.12.015.

Received 14 September 2016

Received in revised form 06 November 2017

Accepted 10 November 2017 